\title{
A Simple and Rapid Method for Quality Control of Major Histocompatibility Complex-Peptide Monomers by Flow Cytometry
}

\author{
P. Anoop Chandran ${ }^{1 *}$, Sonja Heidu', Henning Zelba ${ }^{1}$, Barbara Schmid-Horch ${ }^{2}$, \\ Hans-Georg Rammensee ${ }^{1}$, Steve Pascolo ${ }^{3}$ and Cécile Gouttefangeas ${ }^{1 *}$
}

'Department of Immunology, Interfaculty Institute for Cell Biology, Eberhard Karls University and German Cancer Consortium (DKTK), German Cancer Research Center (DKFZ) Partner Site Tuebingen, Tuebingen, Germany, ${ }^{2}$ Center for Clinical Transfusion Medicine GmbH, University Hospital, Tuebingen, Germany, ${ }^{3}$ Department of Dermatology, University Hospital, Zürich, Switzerland

Major histocompatibility complex (MHC) multimers are essential tools in T cell immunomonitoring, which are employed both in basic and clinical research, as well as for assessing clinical samples during therapy. The generation of $\mathrm{MHC}$ monomers loaded with synthetic peptides is an elaborate and time-consuming process. It would be beneficial to assess the quality of these monomers prior to downstream applications. In this technical note, we describe a novel flow cytometry-based, cell-free, quick, and robust assay to check the quality of $\mathrm{MHC}$ monomers directly after refolding or after long-term storage.

Keywords: MHC-peptide monomers, multimers, antigen-specific T cells, quality control, UV-peptide exchange

\section{INTRODUCTION}

Heterotrimeric major histocompatibility complex (MHC) class I molecules consist of a polymorphic heavy chain, an invariant $\beta 2$-microglobulin light chain and an 8-10 amino acid-long peptide located in the binding groove formed by the heavy and light chains $(1,2)$. T cell receptors (TCRs) expressed at the cell surface of $\mathrm{CD}^{+} \mathrm{T}$ lymphocytes interact very specifically with both their cognate peptide and with the MHC class I, forming the basis of MHC-restriction and antigen-specific T-cell immune response (3).

The peptide-MHC multimer technology makes use of this highly specific interaction and has evolved as an essential tool for monitoring antigen-specific $\mathrm{CD}^{+} \mathrm{T}$ cells (4-9). Recombinant peptide-MHC monomers (monomers) can also be immobilized as artificial antigen presenters to stimulate and expand peptide-specific T cells (10).

The conventional production of monomers is a multi-step process, which involves in vitro refolding of the recombinant heavy chain together with $\beta 2$-microglobulin and the peptide of interest, followed by BirA-dependent biotinylation $(7,11)$. Monomers can then be multimerized using fluorochrome-coupled streptavidin. Meanwhile, a number of commercial suppliers propose various formats of MHC multimers and customized products for specific needs. While such reagents are generally of high-quality, they are expensive. Thus, many laboratories engaged in large-scale monitoring studies prefer in-house production of monomers, which is, however, labor intensive. For high-throughput generation of small quantities of monomers, the UV-based peptide exchange method is preferred (12).

Functionality of monomers and multimers, i.e., specific binding to cognate TCRs, depends on the quality and stability of the refolded complex and its appropriate biotinylation and multimerization. 
Issues that could lead to low-quality monomers/multimers include protein precipitation or aggregation during the in vitro refolding, use of low-affinity or unstable peptides, excess of free biotin, suboptimal biotinylation due to poor enzymatic activity or to cleavage of BirA site by contaminating proteases, poor quality of chromatographic purification of complexes, and incomplete UV-exchange (12). Basic quality control of MHC monomers can be performed by SDS/PAGE-mediated resolution or by liquid chromatography. Both methods can be used to check for the amount and quality of the individual constituents of the MHC complex $(11,13)$, but are of low throughput. Currently, the only high-throughput method available to assess the integrity of a monomer is an ELISA for the detection of $\beta 2$-microglobulin (12). None of these methods can fully report whether the monomers still maintain a functional conformation, which is crucial for their functionality. In this technical note, we describe a flow cytometrybased, novel, quick, high-throughput, and cost-effective assay to assess the quality and integrity of MHC monomers.

\section{MATERIALS AND METHODS}

\section{Antibodies}

The following anti-MHCmonoclonal antibodies (mAbs) were produced and purified in-house from hybridoma cultures. W6/32 and BB7.2 hybridomas were purchased from the European Collection of Authenticated Cell Cultures (ECACC) and the American Type Culture Collection (ATCC), respectively. The B1.23.2 hybridoma was a kind gift from Dr. Bernard Malissen. The HC10 and HCA2 hybridomas were a kind gift from Dr. Hidde Ploegh. The antibodies were used at the indicated pre-tested concentrations: W6/32 (IgG2a, $1 \mu \mathrm{g} / \mathrm{mL})$ (14), BB7.2 (IgG2b, $0.1 \mu \mathrm{g} / \mathrm{mL})$ (15), B1.23.2 (IgG2b, $0.7 \mu \mathrm{g} / \mathrm{mL}$ ) (16), HC10 (IgG2a, $0.6 \mu \mathrm{g} / \mathrm{mL}$ ), and HCA2 (IgG1, $0.5 \mu \mathrm{g} / \mathrm{mL}$ ). Both $\mathrm{HC} 10$ and HCA2 mAbs recognize linear HLA-class I epitopes, and, therefore, bind to free HLA-heavy chains (17-21). As respective isotype-matched negative controls, irrelevant antibodies IgG1 (clone MOPC21), IgG2a (mouse anti-trinitrophenol, clone G155-178), and IgG2b (mouse anti-H2-Kb, clone $\mathrm{Y}-3$ ), were used.

\section{MHC Monomers, UV-Exchange, and Multimers}

Peptides were synthesized in-house using an automated peptide synthesizer 433A (Applied Biosystems, Foster City, CA, USA) (22) and diluted at $10 \mathrm{mg} / \mathrm{mL}$ in $100 \%$ DMSO immediately before use. MHC-peptide monomers were generated by the conventional refolding method as described before: recombinant HLA heavy chains, light chain ( $\beta 2$-microglobulin), and the peptide of interest were refolded, biotinylated, and purified by FPLC (7). To generate non-biotinylated monomers, the biotinylation step was left out of the process. The concentration of the resulting monomers was determined by Bradford assay and reagents were aliquoted and frozen $\left(-80^{\circ} \mathrm{C}\right)$ at $2 \mathrm{mg} / \mathrm{mL}$ concentration. Multimers were generated by incubating the monomers with streptavidin-PE or streptavidin-APC (Thermo Fisher Scientific) at a final 4:1 M ratio $(7)$, aliquoted and frozen $\left(-80^{\circ} \mathrm{C}\right)$ in the presence of glycerol and human serum albumin (23). The method for generation of monomers by UV-exchange has been described previously $(8,12)$. In short, equal volume of UV-sensitive monomer $(200 \mu \mathrm{g} / \mathrm{mL}$ in PBS containing $2 \mathrm{mM}$ EDTA) and of replacement peptide solution $(400 \mu \mathrm{g} / \mathrm{mL}$ in PBS with $2 \mathrm{mM}$ EDTA) were mixed together and incubated for $1 \mathrm{~h}$ under UV-light $(366 \mathrm{~nm})$ in a 96-well microplate (Greiner Bio-one $\mathrm{GmbH}$, Frickenhausen, Germany) using a maximum volume of $130 \mu \mathrm{L}$ per well. After UV-exchange, the plate was centrifuged at 3,300 $\mathrm{g}$ for $5 \mathrm{~min}$ at room temperature and $100 \mu \mathrm{L}$ supernatant was collected from each well. Assuming a yield of $50 \%$, the UV-exchanged monomer had a concentration of $50 \mu \mathrm{g} / \mathrm{mL}$ and was used directly for the bead assay or to generate multimers. When UV-exchange was performed without the replacement peptide, an equal volume of PBS containing $2 \mathrm{mM}$ EDTA/DMSO was used instead. The peptides and monomers used in this study are listed in Table $\mathbf{1 .}$

\section{Bead Assay}

A step-by-step workflow of the assay is shown in Figure 1. First, a $0.1 \mu \mathrm{g} / \mathrm{mL}$ MHC monomer solution was prepared in PBS. Streptavidin-coated microspheres (Cat. No. CP01N, Bangs Laboratories Inc., IN, USA), hereafter referred to as beads, at a concentration of 100,000 beads $/ \mu \mathrm{L}$, were washed twice $(1,300 \mathrm{~g}$, $5 \mathrm{~min}, 4^{\circ} \mathrm{C}$ ) in at least 10 times volume of PBS and resuspended in $100 \mu \mathrm{L}$ FACS buffer/100,000 beads [FACS buffer: PBS (in-house preparation) containing $0.02 \%$ sodium azide, $2 \mathrm{mM}$ EDTA (Roth, Karlsruhe, Germany), and 2\% heat-inactivated FCS]. The monomer solution was then mixed with an equal volume of the bead solution and incubated at $4^{\circ} \mathrm{C}$ for $30 \mathrm{~min}$. A single test, therefore, contained 100,000 beads in a $0.05 \mu \mathrm{g} / \mathrm{mL}$ (10 ng) monomer solution (optimized by titration, see Figure 2). The mixture was then

TABLE 1 | Description of major histocompatibility complex (MHC) monomers and peptides used in this study.

\begin{tabular}{|c|c|c|c|c|}
\hline MHC & Peptide code & Monomer code & Peptide sequence & Source protein \\
\hline HLA-A*02:01 & $\mathrm{A}^{*} 02-$ MelanA & HLA-A*02-MelanA & ELAGIGILTV & Human, MelanA/MART-1 (modified) \\
\hline HLA-B*08:01 & $\mathrm{B}^{\star} 08-\mathrm{EBNA3}$ & HLA-B*08-EBNA3 & FLRGRAYGL & Epstein-Barr virus, EBNA3 protein \\
\hline MHC & Peptide code & Monomer code & Peptide sequence & Description \\
\hline HLA-B*08:01 & $\mathrm{B}^{\star} 08-U V$ & HLA-B*08-UV & FLRGRAJGL & UV-sensitive peptide \\
\hline
\end{tabular}


washed twice with 10 times the volume using FACS buffer by centrifuging $\left(1,300 \mathrm{~g}, 5 \mathrm{~min}, 4^{\circ} \mathrm{C}\right)$. A total of 100,000 monomerloaded beads per test were distributed in a 96-well round-bottom plate and were centrifuged. The beads were then incubated with anti-MHC mAbs or relevant isotype control $\mathrm{mAbs}$ in a final volume of $50 \mu \mathrm{L} /$ test for $30 \mathrm{~min}$ at $4^{\circ} \mathrm{C}$, washed twice with $200 \mu \mathrm{L}$ FACS buffer/test, and then stained with the secondary antibody (goat anti-mouse PE; Jackson ImmunoResearch, PA, USA) for $30 \mathrm{~min}$ at $4^{\circ} \mathrm{C}$. Finally, the beads were washed twice with FACS buffer, resuspended in $200 \mu \mathrm{L}$ FACS buffer, and the PE fluorescence was measured on an LSR-Fortessa SORP (BD).

\section{Acid Treatment of MHC Monomers}

Monomers produced by the conventional refolding method were bound onto the beads and were then denatured by treatment with an acid buffer. One million beads were incubated for $90 \mathrm{~s}$ in $1 \mathrm{~mL}$ acid buffer $(0.3 \mathrm{M}$ glycine $\mathrm{HCl}, 1 \% \mathrm{BSA}$ in sterile water, $\mathrm{pH}$ 2.3) on ice, followed by one wash with 10 times volume PBS (24). Thereafter, the beads were washed twice using PBS and were stained as described above.

\section{Multimer Staining of PBMCs}

To confirm MHC multimer functionality, we used PBMCs from HLA- $\mathrm{A}^{\star} 02^{(+)}$donors 1,3 , and 4 obtained through venipuncture as buffy coats and from donor 2 obtained twice (2a and 2b) through leukapheresis (Center for Clinical Transfusion Medicine $\mathrm{GmbH}$ of the University Hospital in Tuebingen) after informed consent. PBMCs were isolated and stored in liquid nitrogen until use, as described before (4). Cryopreserved PBMCs were thawed and stained essentially following the CIP protocol (http://www.cimt.eu/workgroups/cip) (4). Cells were labeled with CD4 FITC (clone HP2/6, in-house production), CD8 PE-Cy7 (clone SFCI21-Thy2D3, Beckman Coulter), Aqua Live/Dead (Thermo Fisher Scientific), and multimers (PE- or APC-labeled).

\section{Data Acquisition and Analysis}

Within $24 \mathrm{~h}$ after staining and fixation [FACS buffer containing $1 \%$ formaldehyde ( $36 \% \mathrm{w} / \mathrm{v}$; Sigma-Aldrich)], the cells and beads (not fixed) were acquired on an LSR-Fortessa SORP cytometer (BD Biosciences, Heidelberg, Germany) operated through the BD FACSDiva ${ }^{\mathrm{TM}}$ software (version 6.1.2). Spectral overlap was compensated using $\mathrm{AbC}$ and $\mathrm{ArC}$ beads (both from Thermo Fisher Scientific). Ten thousand beads or $1 \times 10^{6}$ cells were acquired per test. The resulting data were saved as FCS 3.0 files and subsequently analyzed using FlowJo Mac version 9.7.5 or Windows version V10 (FlowJo LLC, Ashland, OR, USA).

\section{Gating Strategy and Analysis}

PBMCs were serially gated following the hierarchy: time parameter histogram: cells that were non-linearly acquired over time were "gated out." FSC-A vs. FSC-H dot plot: gate on singlets. FSC-A vs. Aqua Live/Dead dot plot: gate on living cells. FSC-A vs. SSC-A dot plot: gate on lymphocytes. CD8 PE-Cy7 vs. CD4 FITC dot plot: gate on CD4 $4^{(-)}$cells. CD8 PE-Cy7 vs. multimer (PE/APC): quadrant gate to determine $\mathrm{CD} 8^{(+)}$multimer $^{(+)}$cells (see example of a full analysis in Figure S2 in Supplementary Material). Beads were gated from the FSC-A vs. SSC-A plot, and the PE fluorescence was assessed on histogram plots. Respective median fluorescence index (MFI) values are shown in the figures.

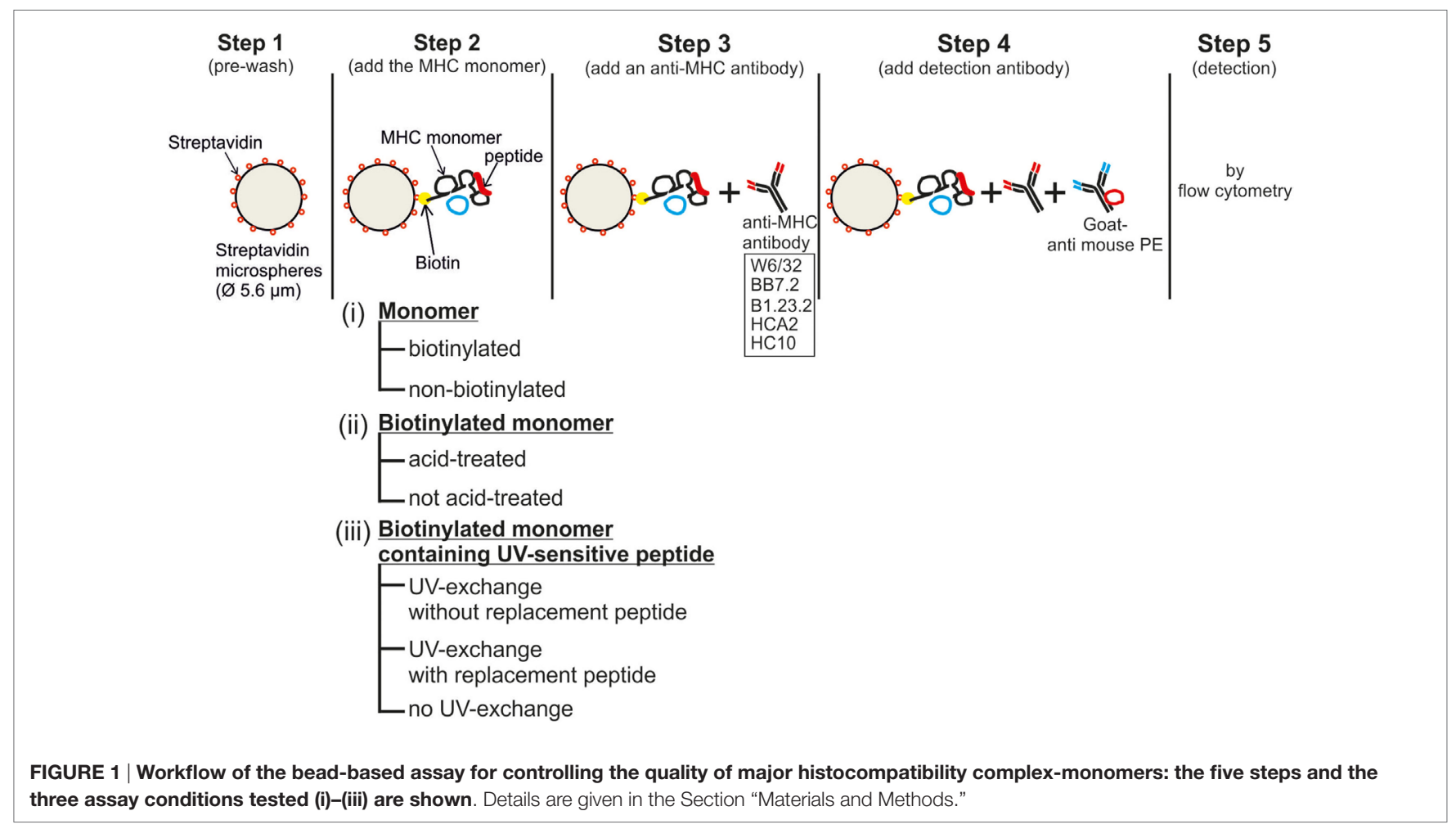




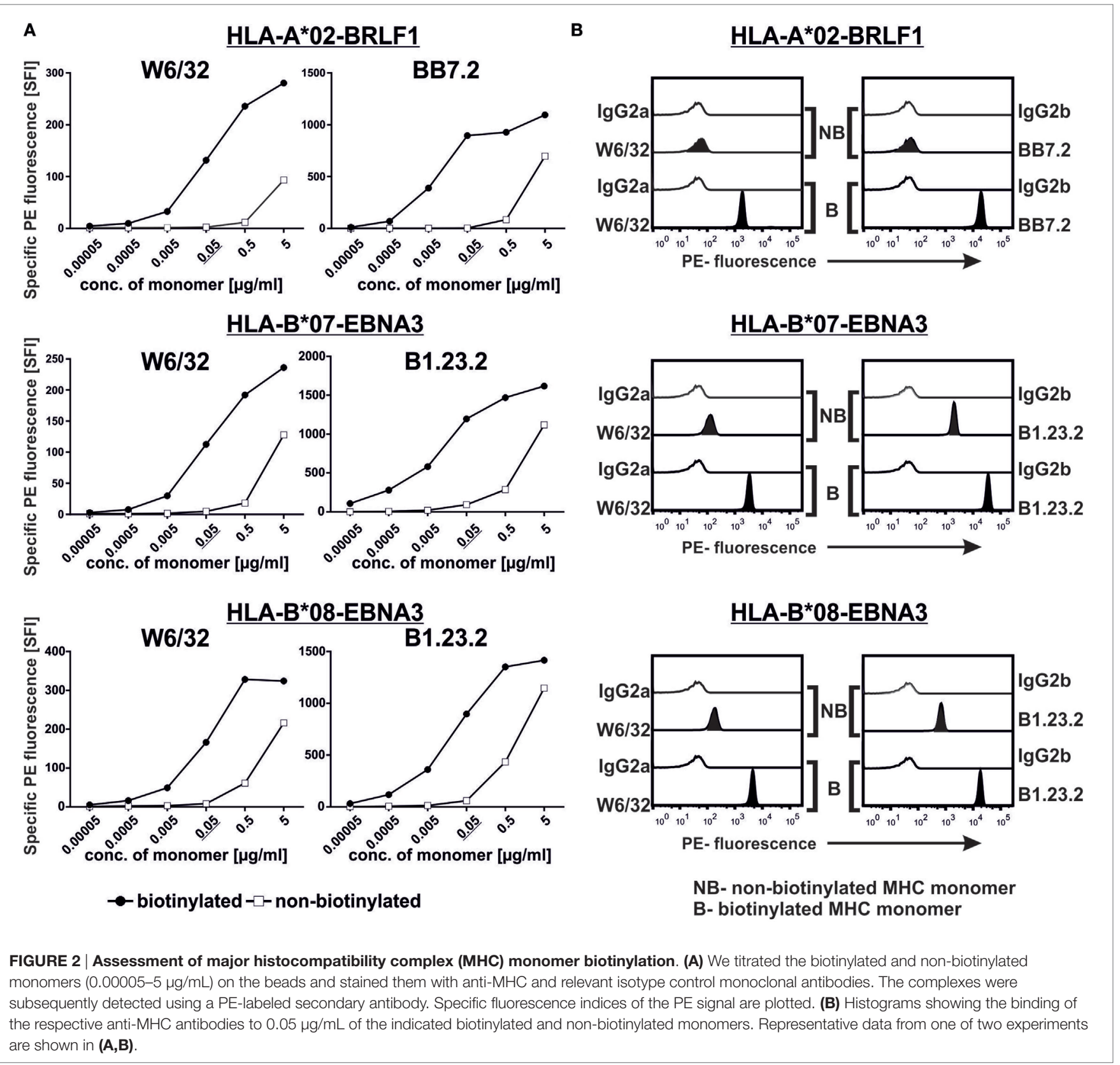

For Figure 2, the specific fluorescence index (SFI) was calculated as the ratio of MFI of the specific antibody to the MFI of the isotype control antibody.

\section{RESULTS}

\section{Principle of the Assay}

The bead-based assay can be used to test two aspects of the MHC monomer integrity, i.e., whether the monomer has been biotinylated and whether the monomer has refolded properly with the peptide. Binding of the monomers to the streptavidin-coated beads indicates their biotinylation. Recognition of an MHC monomer by the three mAbs W6/32, BB7.2, and B1.23.2 should reveal an intact complex (14-16), while the binding of HCA2 and $\mathrm{HC} 10 \mathrm{mAbs}$ indicates an aberration in the heterotrimeric structure of the monomer (17-21).

\section{Non-Biotinylated Monomers Do Not Bind to the Beads}

In order to test whether our assay can differentiate between non-biotinylated and biotinylated monomers, we generated non-biotinylated HLA- $A^{\star} 02,-B^{\star} 07$, and $-B^{\star} 08$ monomers and compared their binding to the beads alongside their respective biotinylated monomers. At high monomer concentrations $(0.5$ and $5 \mu \mathrm{g} / \mathrm{mL}$ ), we observed some unspecific binding of the non-biotinylated monomers and, therefore, titrated down the 
amount of monomer on the beads. At monomer concentrations of $0.05 \mu \mathrm{g} / \mathrm{mL}$, binding of all three non-biotinylated monomers was minimal while all their biotinylated counterparts showed consequent binding as revealed by two specific mAbs (Figure 2A). Hence, this concentration was chosen for the next experiments. We further tested the binding of these monomers in their biotinylated and non-biotinylated forms to confirm that our assay can indeed differentiate them (Figure 2B; Figure S1 in Supplementary Material). As control, PBMCs were stained with multimers generated from the biotinylated and non-biotinylated monomers and as expected, only the biotinylated ones could detect HLA-A ${ }^{\star} 02-B R L F 1$ (Figure S2 in Supplementary Material) and $\mathrm{HLA}_{-} \mathrm{B}^{\star} 07-\mathrm{EBNA} 3$ (data not shown)-binding $\mathrm{CD}^{+}$cells.

\section{The Assay Can Detect the Dissociation of the MHC Complex}

If the complex formed by the MHC heavy chain, $\beta 2$ microglobulin, and peptide happens to dissociate, monomers will become non-functional. This can be the case when synthetic peptides are of low affinity for the MHC. In order to test whether our assay can detect such suboptimal reagents, we artificially denatured MHC complexes by incubating them in a low $\mathrm{pH}$ buffer. We found that binding of W6/32, BB7.2, and B1.23.2 mAbs to acid-treated monomers was considerably reduced, albeit not completely abolished ( $>90 \%$ reduction of MFI, Figure 3). At the same time, damaged monomers were revealed by an increased binding ( $>95 \%$ in MFI) of $\mathrm{mAbs}$ recognizing the free heavy chain, i.e., HCA2 (Figure 3) and $\mathrm{HC10}$ (data not shown).

\section{The Assay Can Report an Unsuccessful UV-Mediated Peptide-Exchange on a Monomer}

To test whether our assay can be used for assessing the quality of monomers produced by UV-exchange, we exposed monomers containing a labile peptide to UV-light in the absence or presence of a replacement peptide. Without peptide addition, W6/32 binding was clearly decreased (MFI loss range: 34-64\%) and HCA2 and HC10 mAb binding was induced as compared to no UV-treatment (Figure 4; Figure S3 in Supplementary Material). Residual binding of W6/32 to the beads might be due to incomplete dissociation of the monomers, as already observed (12). UV-exchange of the monomers in the presence of a relevant peptide prevented HCA2 and $\mathrm{HC} 10$ binding while it restored $\mathrm{W} 6 / 32$ binding for HLA-B ${ }^{\star} 07$ and $-\mathrm{B}^{\star} 08$. Note that the binding of $W 6 / 32$ was not fully restored after addition of three different HLA- $A^{\star} 02$ viral peptides, $A^{\star} 02-B R L F 1$ (Figure 4), $A^{\star} 02-C M V$, and $\mathrm{A}^{\star} 02$-Flu (data not shown); BB7.2 mAb gave similar results for $\mathrm{HLA}-\mathrm{A}^{\star} 02$ binding after $\mathrm{UV}$-exchange (Figure $\mathrm{S} 3 \mathrm{~B}$ in Supplementary Material). Altogether, this suggests that the most reliable measure of an effective UV-exchange is the lack of binding of $\mathrm{HC} 10$ and HCA2, rather than the binding of the W6/32 mAb. Furthermore, only the multimers generated from monomers that

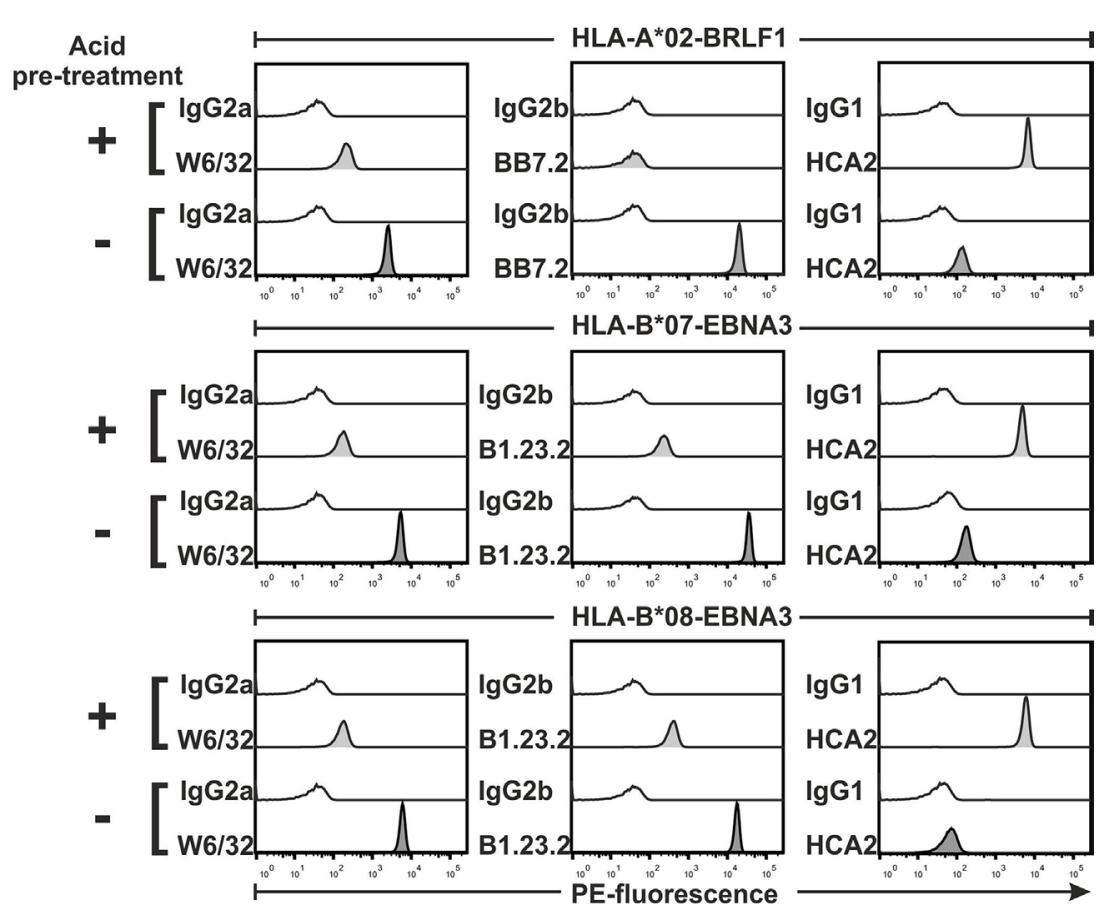

FIGURE 3 | Detection of denatured major histocompatibility complex (MHC) monomers. Beads were loaded with monomers, treated with an acidic buffer or with PBS (control), and then stained with the indicated anti-MHC monoclonal antibodies and relevant isotype controls, followed by detection with a PE-labeled secondary antibody. Representative histograms of PE fluorescences from one of two experiments are shown. 


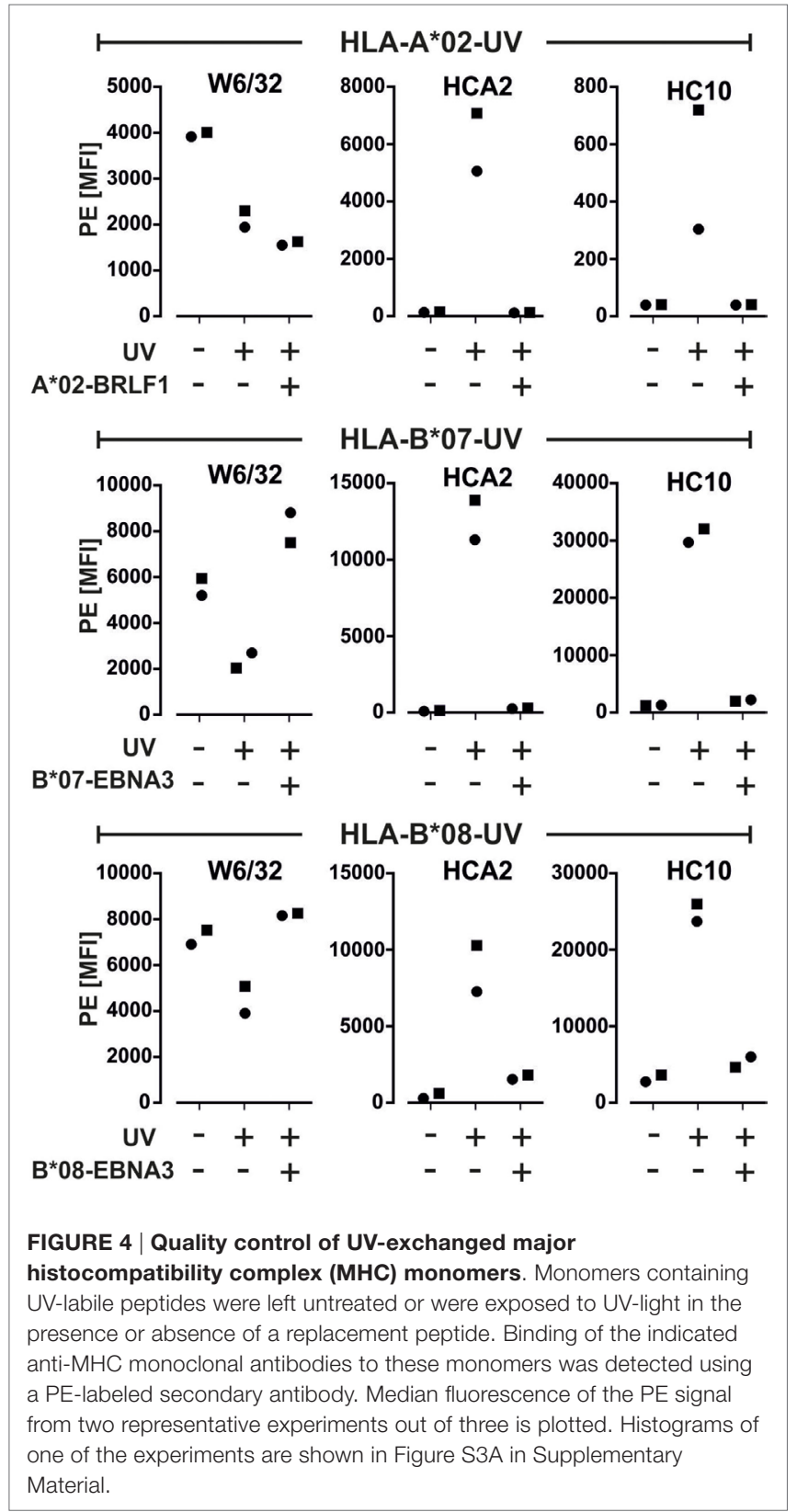

were UV-exposed in the presence of a replacement peptide were able to stain antigen-specific cells within PBMCs (Figure S2 in Supplementary Material).

\section{Exemplary Application of the Assay}

When PBMCs were tested with multimers that were generated from two frozen batches of HLA-A*02-MelanA monomers, we noticed that Batch 1 multimers did not stain any MelanAspecific T cells while Batch 2 monomers did (Figure 5A). As a demonstration of how the assay is useful for controlling the quality of $\mathrm{MHC}$ monomers, we tested the two monomer batches with the bead assay. As shown in Figure 5B, W6/32 and BB7.2 mAbs bound to Batch 2, but not Batch 1 monomers. This indicated that only Batch 2 monomers maintained an intact heterotrimeric MHC conformation. Batch 1 monomer also did not bind to HCA2 antibodies, suggesting a degradation of the MHC heavy chain as well. This was later confirmed by FPLC (data not shown). Hence, the assay can be used to control the integrity of monomers that have been stored at $-80^{\circ} \mathrm{C}$ for longer periods.

\section{DISCUSSION}

Major histocompatibility complex monomers have revolutionized $\mathrm{T}$ cell immunology by allowing sensitive and robust detection of antigen-specific $\mathrm{CD}^{+} \mathrm{T}$ cells. Structural integrity of $\mathrm{MHC}$ monomers is crucial for their functionality and downstream applications. Therefore, quality control measures following production are essential. Although several tests exist to assess monomers, none of them really pinpoint their functionality in a quick, simple, and high-throughput manner. Testing the binding of MHC multimers on cells is by far the ultimate test; however, generating a cell bank of specific T cells is cumbersome and impractical for high-throughput screenings and epitope discovery purposes. Catering to the need for a cheap and quick way to report the integrity of monomers, we established a flow cytometry-based assay.

The two main applications of MHC monomers, i.e., fluorescent MHC multimers for flow cytometry analysis and artificial antigen presenting cells for $\mathrm{T}$ cell priming, use biotinylated forms of the MHC monomer. The principle of the assay is to load monomers on streptavidin-coated microspheres and subsequently label these beads using anti-MHC antibodies. This bead-monomer-antibody complex can then be detected on a flow cytometer with a fluorescent secondary antibody (Figure 1). Hence, both the biotinylation status and the functional heterotrimeric conformation of a MHC monomer can be assessed.

To establish test conditions, we first determined optimal antibody and monomers concentrations to be used (both depend on the binding capacity of the beads, which might vary between batches). By using $0.05 \mu \mathrm{g} / \mathrm{mL}$ of monomers, we could clearly discriminate between biotinylated and non-biotinylated monomers (Figure 2). The assay can detect denaturation of MHC complexes by using a minimum combination of two anti-MHC antibodies, one that detects free heavy chains (HCA2 or $\mathrm{HC} 10$ ) and another that detects heterotrimeric $\mathrm{MHC}$ complexes (W6/32, BB7.2, or B1.23.2). This was demonstrated by denaturation of monomers with a brief acid treatment (Figure 3) or by UV-exposure without addition of a replacement peptide (Figure 4). It is worth noting that, although it was described previously that HCA2 binds free HLA-A and HC10 binds free HLA-B and C chains (17-21), we observed that upon acid denaturation, HCA2 binds strongly to HLA$\mathrm{A}^{\star} 02, \mathrm{HLA}-\mathrm{B}^{\star} 07$, and HLA-B ${ }^{\star} 08$ molecules, while $\mathrm{HC} 10$ reacts strongly with $\mathrm{HLA}-\mathrm{B}^{\star} 07$ and $-\mathrm{B}^{\star} 08$ and very weakly with $-\mathrm{A}^{\star} 02$ (Figure 4). Therefore, we recommend using a combination of several relevant anti-MHC antibodies to unambiguously monitor monomers prepared with different HLA heavy chains using the conventional or the UV-exchange method, before they are 

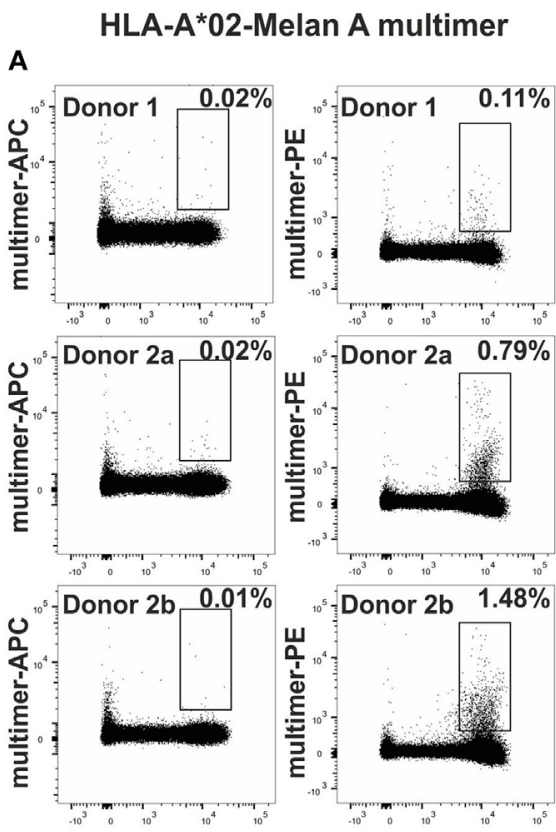

CD8 PE-Cy7

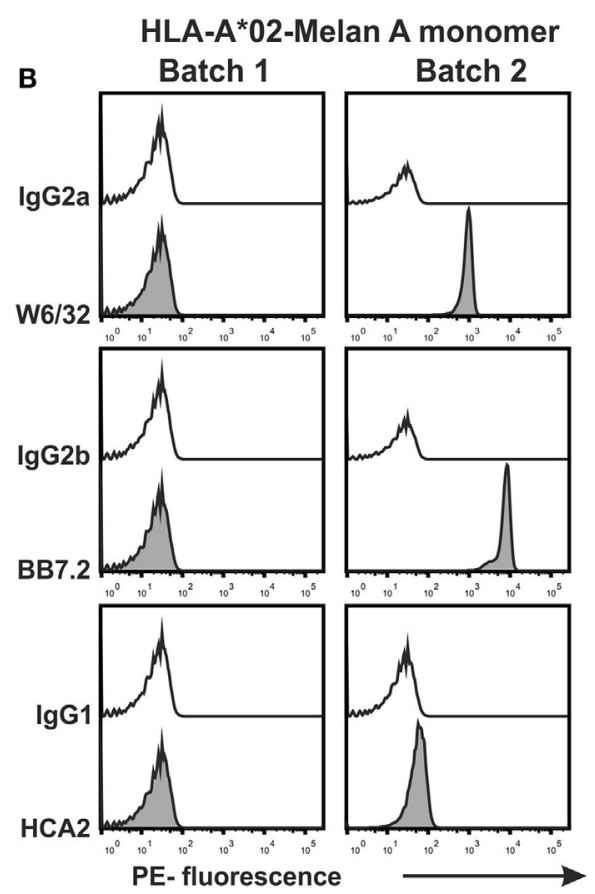

FIGURE 5 | Application of the bead assay to test in-house produced major histocompatibility complex (MHC) monomers. TwO batches of conventional HLA-A*02 monomers (Batch 1 and Batch 2), each generated with the Melan A peptide (ELAGIGLTV) were tested. (A) PBMCs from two HLA-A02(+) donors (indicated) were stained with APC-labeled MHC multimers generated from Batch 1 and PE-labeled MHC multimers generated from Batch 2. MultimerAPC/PE vs. CD8 PE-Cy7 dot plots are shown. (B) Fluorescence histograms obtained in the bead test.

used to generate MHC multimers or for other applications (Figure 5). Although we have demonstrated the feasibility of this assay using purified $\mathrm{mAb}$ in combination with a secondary $\mathrm{Ab}$, one may also use fluorescence-conjugated anti-HLA Abs (Figure S4 in Supplementary Material). Of note, the assay is not able to check for peptide identity, but can be complemented by determination of the peptide sequence using mass spectrometry (data not shown).

A clear advantage of this approach is the minimal amount of MHC monomer that is needed; by including appropriate isotype control stainings, we used $60 \mathrm{ng}$ of monomer per experiment, which is far lower than what is generally required for SDS-PAGE analysis (10-20 $\mu \mathrm{g}$ ) or for ELISA (approximately $300 \mathrm{ng}$ ). Another advantage is the ease of read-out via flow cytometry, which enables high-throughput quality assessment. The assay is quick and requires less than $2 \mathrm{~h}$ for sample preparation and less than $1 \mathrm{~h}$ for measurement and analysis, which is much shorter than the ELISA method which needs approximately $8 \mathrm{~h}$ (12). Additionally, in our hands, the ELISA method displays some intra-assay variability. Finally, the new assay is cost-effective and requires few reagents and specialized equipments. Although we described in this report a qualitative assessment of MHC monomers, it should also be feasible to quantify the amount of functional monomers by generating standard curves using reference MHC monomers of known concentrations. Altogether, we recommend this assay as a fast, robust, and affordable method to assess MHC monomers at the production step and upon long-term storage.

\section{AUTHOR CONTRIBUTIONS}

PAC designed the experiments, analyzed the data, and wrote the manuscript. SH performed the experiments. HZ assisted the experiment design. BS-H provided blood samples. H-GR supervised the study. SP devised the concept of the assay. CG supervised the entire study and wrote the manuscript.

\section{ACKNOWLEDGMENTS}

We thank Stefan Stevanović and his team for providing the synthetic peptides and Claudia Falkenburger for antibody production. We also thank Juliane Schneider for her critical evaluation of the written manuscript.

\section{FUNDING}

CG and PAC are supported by the Deutsche Forschungsgemeinschaft, SFB685 project Z05, H-GR by the DKTK, and the ERC grant (Mutaediting) and CG by the Wallace Coulter Foundation.

\section{SUPPLEMENTARY MATERIAL}

The Supplementary Material for this article can be found online at http://journal.frontiersin.org/article/10.3389/fimmu. 2017.00096/full\#supplementary-material. 


\section{REFERENCES}

1. Bjorkman PJ, Saper MA, Samraoui B, Bennett WS, Strominger JL, Wiley DC. Structure of the human class I histocompatibility antigen, HLA-A2. Nature (1987) 329:506-12. doi:10.1038/329506a0

2. Falk K, Rotzschke O, Stevanovic S, Jung G, Rammensee HG. Allele-specific motifs revealed by sequencing of self-peptides eluted from MHC molecules. Nature (1991) 351:290-6. doi:10.1038/351290a0

3. Matsui K, Boniface JJ, Reay PA, Schild H, Fazekas de St Groth B, Davis MM. Low affinity interaction of peptide-MHC complexes with $\mathrm{T}$ cell receptors. Science (1991) 254:1788-91. doi:10.1126/science.1763329

4. Chandran PA, Laske K, Cazaly A, Rusch E, Schmid-Horch B, Rammensee HG, et al. Validation of immunomonitoring methods for application in clinical studies: the HLA-peptide multimer staining assay. Cytometry B Clin Cytom (2016). doi:10.1002/cyto.b.21397

5. Blanchfield JL, Shorter SK, Evavold BD. Monitoring the dynamics of T cell clonal diversity using recombinant peptide:MHC technology. Front Immunol (2013) 4:170. doi:10.3389/fimmu.2013.00170

6. Wooldridge L, Lissina A, Cole DK, van den Berg HA, Price DA, Sewell AK. Tricks with tetramers: how to get the most from multimeric peptide-MHC. Immunology (2009) 126:147-64. doi:10.1111/j.1365-2567.2008.02848.x

7. Altman JD, Moss PA, Goulder PJ, Barouch DH, McHeyzer-Williams MG, Bell JI, et al. Phenotypic analysis of antigen-specific T lymphocytes. Science (1996) 274:94-6. doi:10.1126/science.274.5284.94

8. Andersen RS, Kvistborg P, Frosig TM, Pedersen NW, Lyngaa R, Bakker AH, et al. Parallel detection of antigen-specific $\mathrm{T}$ cell responses by combinatorial encoding of MHC multimers. Nat Protoc (2012) 7:891-902. doi:10.1038/ nprot.2012.037

9. Barnes E, Ward SM, Kasprowicz VO, Dusheiko G, Klenerman P, Lucas M. Ultra-sensitive class I tetramer analysis reveals previously undetectable populations of antiviral CD8+ T cells. Eur J Immunol (2004) 34:1570-7. doi:10.1002/eji.200424898

10. Walter S, Herrgen L, Schoor O, Jung G, Wernet D, Buhring HJ, et al. Cutting edge: predetermined avidity of human CD8 T cells expanded on calibrated MHC/anti-CD28-coated microspheres. JImmunol (2003) 171:4974-8. doi:10.4049/jimmunol.171.10.4974

11. Garboczi DN, Hung DT, Wiley DC. HLA-A2-peptide complexes: refolding and crystallization of molecules expressed in Escherichia coli and complexed with single antigenic peptides. Proc Natl Acad Sci U S A (1992) 89:3429-33. doi:10.1073/pnas.89.8.3429

12. Rodenko B, Toebes M, Hadrup SR, van Esch WJ, Molenaar AM, Schumacher $\mathrm{TN}$, et al. Generation of peptide-MHC class I complexes through UV-mediated ligand exchange. Nat Protoc (2006) 1:1120-32. doi:10.1038/ nprot.2006.121

13. Hadrup SR, Toebes M, Rodenko B, Bakker AH, Egan DA, Ovaa H, et al. High-throughput T-cell epitope discovery through MHC peptide exchange. Methods Mol Biol (2009) 524:383-405. doi:10.1007/978-1-59745450-6_28

14. Parham P, Barnstable CJ, Bodmer WF. Use of a monoclonal antibody (W6/32) in structural studies of HLA-A,B,C, antigens. J Immunol (1979) 123:342-9.
15. Parham P, Brodsky FM. Partial purification and some properties of BB7.2 A cytotoxic monoclonal antibody with specificity for HLA-A2 and a variant of HLA-A28. Hum Immunol (1981) 3:277-99. doi:10.1016/0198-8859(81) 90065-3

16. Rebai N, Malissen B. Structural and genetic analyses of HLA class I molecules using monoclonal xenoantibodies. Tissue Antigens (1983) 22:107-17. doi:10.1 111/j.1399-0039.1983.tb01176.x

17. Hutter H, Hammer A, Blaschitz A, Hartmann M, Ebbesen P, Dohr G, et al. Expression of HLA class I molecules in human first trimester and term placenta trophoblast. Cell Tissue Res (1996) 286:439-47. doi:10.1007/ s004410050713

18. Perosa F, Luccarelli G, Prete M, Favoino E, Ferrone S, Dammacco F. Beta 2-microglobulin-free HLA class I heavy chain epitope mimicry by monoclonal antibody HC-10-specific peptide. JImmunol (2003) 171:1918-26. doi:10.4049/jimmunol.171.4.1918

19. Seitz C, Uchanska-Ziegler B, Zank A, Ziegler A. The monoclonal antibody HCA2 recognises a broadly shared epitope on selected classical as well as several non-classical HLA class I molecules. Mol Immunol (1998) 35:819-27. doi:10.1016/S0161-5890(98)00077-7

20. Stam NJ, Spits H, Ploegh HL. Monoclonal antibodies raised against denatured HLA-B locus heavy chains permit biochemical characterization of certain HLA-C locus products. J Immunol (1986) 137:2299-306.

21. Stam NJ, Vroom TM, Peters PJ, Pastoors EB, Ploegh HL. HLA-A- and HLA$\mathrm{B}$-specific monoclonal antibodies reactive with free heavy chains in western blots, in formalin-fixed, paraffin-embedded tissue sections and in cryoimmuno-electron microscopy. Int Immunol (1990) 2:113-25. doi:10.1093/ intimm/2.2.113

22. Peper JK, Schuster H, Loffler MW, Schmid-Horch B, Rammensee HG, Stevanovic S. An impedance-based cytotoxicity assay for real-time and label-free assessment of T-cell-mediated killing of adherent cells. J Immunol Methods (2014) 405:192-8. doi:10.1016/j.jim.2014.01.012

23. Hadrup SR, Maurer D, Laske K, Frosig TM, Andersen SR, Britten CM, et al. Cryopreservation of MHC multimers: recommendations for quality assurance in detection of antigen specific T cells. Cytometry A (2015) 87:37-48. doi:10.1002/cyto.a.22575

24. Shi Y, Smith KD, Lutz CT. TAP-independent MHC class I peptide antigen presentation to alloreactive CTL is enhanced by target cell incubation at subphysiologic temperatures. J Immunol (1998) 160:4305-12.

Conflict of Interest Statement: The authors declare that the research was conducted in the absence of any commercial or financial relationships that could be construed as a potential conflict of interest.

Copyright (c) 2017 Chandran, Heidu, Zelba, Schmid-Horch, Rammensee, Pascolo and Gouttefangeas. This is an open-access article distributed under the terms of the Creative Commons Attribution License (CC BY). The use, distribution or reproduction in other forums is permitted, provided the original author(s) or licensor are credited and that the original publication in this journal is cited, in accordance with accepted academic practice. No use, distribution or reproduction is permitted which does not comply with these terms. 